\title{
Product Introduction Strategies in the Age of Social Media
}

\author{
Rajiv Mukherjee \\ Cox School of Business \\ Southern Methodist University \\ rmukherjee@smu.edu
}

\begin{abstract}
When an incumbent faces a new entrant with superior capabilities, it may preemptively announce (preannounce) its future product to avoid forfeiting users. The traditional focus of preannouncement literature has been on truth-telling and vaporware. In the age of social media, the proliferation of online discussion forums and social network usage leads to the formation of public opinions (signals) that may not be in sync with firm's private information regarding its forthcoming innovation. Further, vigilance by consumers and media outlets induce high ex-post cost on vaporware making it infeasible in such settings. Then, when should firm announce or remain silent in modern settings? Under what conditions should the firm pursue innovation in presence of uncertainties in public signals in addition to its own private information? How does presence of network effects influence the preannouncement strategy of the firm? We find that the incumbent follows a preannouncement strategy (truth-telling or silence) if the public signal associated with it is moderate. Further, network effects has a negative impact on prices and incumbent may innovate only if the entrant's relative ability to leverage network effects is low.
\end{abstract}

Keywords: preannouncement, network effect, competition, signaling, silentware, product differentiation.

\section{Introduction}

Consumers frequently face the dilemma of choosing to stay with their current firm or migrate to a competing firm with superior technology. To combat competition from a new entrant, an incumbent firm may preempt the market with an announcement (preannouncement) of its future innovation. The purpose of a preannouncement is to provide a signal to the market, especially its existing user base that there is value in delaying their decision to switch until the promised time of delivery.

The extant literature on product introduction through preannouncements has focused on true preannouncement, strategic false preannouncement (vaporware) and no preannouncement. With the advent of social media, consumers form belief regarding the success of the preannouncement based on discussions on consumer forums and other social media platforms. Sentiments on such platforms driven by user generated content leads to public opinion regarding a firm's future product (capability, quality, features, pricing, etc.). While such a public signal can be somewhat controlled by making a truthful preannouncement, positive or negative sentiments regarding a product could spread rapidly through social media leading to discordant beliefs regarding its success. In case the firm chooses to remain silent, in absence of a clear commitment, such public opinions are often based on strategic or undesired product information leaks by the firm, its competition or other sources. The traditional focus of preannouncement literature in economics, marketing and information systems has been on vaporware. However, with anti-trust laws and the power of opinion formation of new age media channels (such as public forums, social networks, vigilant media houses tracking vaporware e.g., Wired Magazine Vaporware Awards), firms now rarely indulge in strategic false preannouncements due to the high expost cost of vaporware. Thus, in the modern era of social media, based on truthful preannouncement or the lack of it, public signals generated through such channels can lead to over optimism or strong pessimism regarding a product. The role of such public signals on preannouncement strategies has not been sufficiently addressed in the extant literature and forms the primary focus area of this paper.

Further, products in several industries such as software and consumer electronics are characterized by network effects where the value of the product increases with the number of its users [16]. The extant literature is not clear regarding the role of network effects on preannouncement strategies in product markets. While some suggest that the 
presence of network effects makes preannouncement beneficial for the firm, others have shown the benefits of silence in such settings. The extant literature has not studied the role of network effects on preannouncement strategies in presence of uncertainties in public and private signals in settings that characterize the modern technology landscape in the age of social media. We explore the role of network effects in such settings and this forms the second focus of this paper.

While truthful preannouncement may help the incumbent manage consumer expectations better, it may attract undesired strategic behavior from the new entrant firm (e.g., competitive pricing). By contrast, while silence may be useful for the incumbent in misleading competing firms, it could have a detrimental effect of not being able to manage consumer expectations in the desired manner. Thus, an incumbent firm must take into consideration the expectations of consumers as well as that of a competitor before choosing its preannouncement strategy. The following examples from the consumer electronics market illustrate the challenges firms face in choosing their preannouncement strategy.

In 2010, when Apple's marked its entry into the tablet market with the announcement of iPad, the incumbent HP was still working on its next innovation HP Slate 500. HP chose not to preannounce and remained silent regarding its product's features. However, HP's silent strategy did not go down well with consumers and even impacted its stock prices negatively [27]. Given that HP was the market leader in this segment at that point in time, should HP have preannounced its forthcoming product features truthfully?

A contrasting future event involving the two firms provides additional insight. In 2011, Apple announced its next version iPad 2. In response HP preannounced HP TouchPad with clear commitment to specific product features. The preannouncement led to a strong public signal regarding the success of the future product. Media covering technology products considered HP TouchPad to be "twice as powerful" and have "a better piece of software" [28]. Consumer sentiments on public forums were also positive and they felt that "HP has the money and market share to make their product a success" and were willing to delay their purchase decision till the release of HP TouchPad [29]. We now know that in spite of undertaking R\&D efforts, HP failed to deliver and Apple became the market leader in tablet industry. However, HP was indeed successful in creating dilemma among HP tablet users who delayed their switching decision [30,31]. Why did HP's strategy of making a committed preannouncement work but its silent innovation strategy fail? Given HP's strong reputation based on market share at that time it is indeed possible that public signal associated with announcement strengthened consumer belief in the product's successful delivery while its silence may have led to rumor mill resulting in a weak public signal associated with product success. In addition to the public signal, the firm must consider its private signal regarding the success of its innovation before devising its preannouncement strategy.

The incumbent firm has good understanding regarding the true chance of success of its future product (a private signal) and bases its decision to undertake development and preannouncement strategy accordingly. Our insights into the interplay between the private and public signal on preannouncement strategy is another aspect of our research contribution.

We find that the incumbent innovates when its private signal is sufficiently high. Such an incumbent engages in a truthful preannouncement strategy if the associated public signal is moderate. For low or high values of public signal, the innovating firm will be silent. By contrast, if the public signal is moderate, the incumbent firm will engage in a silent strategy, otherwise it shall preannounce. We show that the ability of firms to leverage network effects has a negative impact on prices, and the incumbent firm innovates only when the entrant's ability to leverage network effects is low.

The rest of the paper is organized as follows. We discuss relevant literature in Section 2. The model is described in section 3 and sections 4 and 5 encompasses the analysis. We conclude the paper in Section 6.

\section{Relevant Literature}

Preannouncement is a signaling strategy used by firms to target users before the actual launch of the product [13]. Unlike announcements few weeks before the official launch of the product, a preannouncement is specifically targeted to preempt the market and prevent customers from switching to a rival product. The extant literature on new product preannouncement (NPP) does not distinguish between the two, leading to discordant results of the impact of preannouncement strategies [20]. The focus of the NPP literature has been on the decision to preannounce $[4,7,23,26]$, timing of preannouncement $[17,19,20]$, rationale behind preannouncement $[8,13]$ and content of the preannouncement [24]. Other studies have studied diffusion of preannounced products [25], vaporware [2,6] and user welfare [11, $12,18]$. 
The preemption literature discusses firm strategies for product pricing, preannouncement, timing and markets without network externalities [3, 9,10]. Gerlach [12] discusses the effect of announcement by a new entrant and the resulting reaction of the incumbent to preempt by cutting prices in a market where users have switching costs. In equilibrium, the new entrant does not always announce, and not announcing increases the ex-ante total welfare. Gerlach [12] also shows that users can be better off with a ban on announcement. Choi et al. [5] show that incentive for preannouncements are stronger in markets with network effects. In such markets preannouncements can be used to induce the delay of users' purchases and forestall the build-up of rival products' installed bases. The extant literature suggests that 'vague' preannouncements [20] may not have a strong influence on users and that information should be clear and informative. However, the literature also acknowledges that firms may not have an incentive to make clear preannouncements for the fear of product cannibalization, loss of reputation due to inability to deliver, and reaction from competition. The costs and benefits of preannouncement are different for users and firms, and these are less explored issues especially in a market where the new entrant arrives with a superior technology and where there is uncertainty regarding incumbent's ability to successfully deliver a preannounced technology on time [20].

While a firm may be truthful in its intention and fail to deliver, it may also choose to strategically lie about its intention to deliver in the future. In the computer hardware and software industry, such false preannouncements are called 'vaporware' $[12,15]$. In the late 1980s, vaporware had reached epidemic proportions [21]. As a result, a council was formed in 1990 with several firms including HP and Sybase to issue a report to discourage 'vaporware' because of its negative impact on the industry's capability [22]. With antitrust laws in place, press following preannouncements closely (e.g., Wired Magazine Vaporware Awards) and social media giving the users a common platform to express their opinion and discontent, the high ex-post cost of 'vaporware' makes it an infeasible preannouncement strategy in many industries. In this paper, when an incumbent faces a new entrant technology, we are particularly interested in its choice from two possible preannouncement strategies: (i) truthful preannouncement and (ii) no preannouncement (silence). When the firm is silent, it is however possible that it undertakes product development efforts. It should be noted that even though the firm preannounces truthfully, it may still fail to deliver due to unforeseen circumstances such as failure in supply chain, R\&D efforts etc. In the event of such failure, the firm incurs an ex-post cost for its failure and its ability to price its product is also impacted negatively. A sufficiently high ex-post cost addresses moral hazard issues that a firm may have.

Our work attempts to bridge a gap in extant literature by analyzing the effect of uncertainty regarding the success of an innovation (public and private signals) and network effects on a firm's decision to innovate and preannounce. Based on several factors such as incumbent's reputation, technology ceiling, information dissemination through channels such as social media and online discussion forums, incumbent's preannouncement strategy, etc. a public opinion (signal) is formed regarding the feasibility of delivery of the next technology frontier by the incumbent. Further, a firm also has a private signal regarding its success through better understanding of it organizational capabilities.

With the predominant role of social media in formation of public signals regarding a future product's success, it is crucial for firms to understand how to incorporate both private information and public sentiment to design its preannouncement strategy. We identify preannouncement strategies under different levels of private and public signals in our model. Further, in several industries such as consumer electronics, software, etc. products are characterized by network effects. Unlike extant literature that proposes that network effects creates stronger motivation for preannouncement, we find scenarios where network effects hinders preannouncement, and innovation by the incumbent depends not only on network effects but on the relative ability of the firms to leverage network effects.

\section{Model Description}

Using a stylized three stage model, we study a duopoly of competing on product/service innovation capability in a market with network effects, i.e., the firm's product offering becomes more attractive and valuable as more consumers adopt and use it. Consumers are horizontally differentiated in their taste for product characteristics and are uniformly distributed along a Hotelling line [14] between 0 and 1 , with transportation cost parameter $t$ representing their taste preference and disutility from being a unit distance away from their ideal product preference. This is consistent with the scenarios in consumer electronics and other markets of interest where consumers are driven by their taste preferences. 
Consumers derive additive utility from - (i) an intrinsic value from the capability offered by the incumbent, and (ii) value from network effects generated by the product/service. This assumption on utility function is consistent with characteristics of several markets such as cellphones, tablets etc. where devices have an inherent capability and can also be used to communicate or collaborate with other users in the network to leverage network effect. The incumbent (entrant) firm's ability to leverage network effect is represented by network effect parameter $\alpha_{i}\left(\alpha_{e}\right)[1]$. For example, if the marketshare of the incumbent's product is $m$, then the value derived from the network effect is $\alpha_{i} m$ where $\alpha_{i}>0$ and $0<m<1$. Higher the network effect parameter, greater is the ability of the firm to leverage network effect and provide higher network effects to its consumers [16].

In stage 0 , the incumbent located at one extreme of the Hotelling line covers the market with capability $c$. In stage 1 , a new entrant firm locates itself at the other extreme of the Hotelling line and offers a superior capability $c+\Delta_{e}$. The incumbent at this stage is faced with three decisions - Should it undertake innovation efforts? If the incumbent innovates, then should it preannounce its future delivery in stage 2 and what price should it charge for its product/service in both stages? The incumbent has a private signal $\sigma(0<\sigma<1)$ regarding the probability of its successful innovation. Thus, with probability $\sigma$ it can deliver $c+\Delta_{i}$ in stage 2. If the incumbent fails in its innovation efforts, it continues to maintain its version of the product with capability $c$ in stage 2 . The innovation $\Delta_{i}$ that the incumbent may undertake is common knowledge (consider it to be the next frontier in technology) and is known to the entrant as well as consumers. However, the entrant and consumers do not know $\sigma$ but get a signal $\psi_{A}$ if the incumbent preannounces and $\psi_{s}$ if the incumbent is silent. $\psi_{A}\left(\right.$ or $\left.\psi_{S}\right)$ are probabilities that the entrant and consumers associate with the successful delivery of $c+\Delta_{i}$ by the incumbent in stage 2 if the incumbent preannounces (or is silent). The incumbent is aware of the public signal based on its preannouncement strategy. Having recently delivered a technology, we assume that the entrant is not in a position to undertake R\&D efforts for the next technology frontier [20]. Such inability of the entrant is common in industries where the incumbent is a large firm with an installed base while the new entrant is a start-up firm or in an industry where technology has reached a saturation point in the short run and new innovation takes sufficient time and effort. The entrant, however can use price as a strategic lever to compete against the incumbent in stages 1 and 2 . In stage 2 , the incumbent's new version of the product (if innovation was undertaken successfully) is revealed. Consumers re-valuate their adoption decisions based on available technology and pricing. If the incumbent fails to deliver in spite of preannouncement in stage 1 , it suffers a reputation cost in stage 2 . We begin our analysis with stage 2 (in Section 4) and evaluate the equilibrium prices and market shares depending on its preannouncement strategies. We then analyze stage 1 (in Section 5) to determine market characteristics suitable for incumbent's preannouncement strategies.

\section{Stage 2 Analysis}

We analyze stage 2 based on three possible strategies in stage 1 - (i) Strategy $A$ - when the incumbent preannounces in stage 1, (ii) Strategy $S I$ - when the incumbent silently innovates in stage 1 , and (iii) Strategy $S$ - when the incumbent is silent and does not innovate. The incumbent firm sets prices after realization of success of innovation (if undertaken) and the entrant firm reacts accordingly. Consumers observe the revised prices and revisit their adoption decisions in stage 2 .

\subsection{Incumbent Preannounced in Stage 1}

The utility of a consumer indifferent between the incumbent and the new entrant in stage 2 is given as

$$
\begin{aligned}
& U_{i 2 A}=c+\Delta_{i}+\left(\alpha_{i}-t\right) m_{2 A}-p_{i 2 A} \\
& U_{e 2 A}=c+\Delta_{e}+\left(\alpha_{e}-t\right)\left(1-m_{2 A}\right)-p_{e 2 A}
\end{aligned}
$$

In equation(1.1), $m_{2 A}$ is the incumbent's equilibrium market share of consumers and $p_{i 2 A}\left(p_{e 2 A}\right)$ is the equilibrium price that the consumers are willing to pay to the incumbent (entrant). The profits of the two competing firms are given as

$$
\begin{aligned}
& \pi_{i 2 A}=p_{i 2 A} m_{2 A} \\
& \pi_{e 2 A}=p_{e 2 A}\left(1-m_{2 A}\right)
\end{aligned}
$$

Similarly, the utility of consumers and profits of firms when the incumbent fails to deliver in stage 2 in spite of preannouncement in stage 1 are 


$$
\begin{gathered}
U_{i 2 \bar{A}}=c+\left(\alpha_{i}-t\right) m_{2 \bar{A}}-p_{i 2 \bar{A}} \\
U_{e 2 \bar{A}}=c+\Delta_{e}+\left(\alpha_{e}-t\right)\left(1-m_{2 \bar{A}}\right)-p_{e 2 \bar{A}} \\
\pi_{i 2 \bar{A}}=p_{i 2 \bar{A}} m_{2 \bar{A}}-\psi_{A} m_{1 A} \\
\pi_{e 2 \bar{A}}=p_{e 2 \bar{A}}\left(1-m_{2 \bar{A}}\right)
\end{gathered}
$$

In equation(1.4), $\psi_{A} m_{1 A}$ is the reputation cost that the firm bears when it fails to deliver in spite of a public signal $\psi_{A}$. Incumbent's failure to deliver in stage 2 impacts all users who chose not to switch to the entrant in stage $1\left(m_{1 A}\right)$ based on the preannouncement. For simplicity, we assume a simple cost function that signifies that the cost increases in the number of users who remained with the incumbent and becomes intensified with the public signal $\psi_{A}$. This ex-post cost ensures that moral hazard is not an issue. In other words, if external factors such as vigilant media and consumer discussion on social media channels is not a sufficient deterrent for the firm to engage in vaporware, this technical aspect of the model can ensure that 'vaporware' is indeed an infeasible strategy. Note that development cost for innovation is undertaken in stage 1 . We can solve for the equilibrium market share (as a function of prices) by equating equations(1.1) and(1.3). Simultaneously solving the first order conditions of profits with respect to the respective firm's price we can compute the equilibrium prices [1].

\subsection{Incumbent Silently Innovated in Stage 1}

The utilities of the indifferent consumer upon success or failure of the incumbent are similar to equations (1.1) and (1.3). The equilibrium market share of users upon successful delivery of $c+\Delta_{i}$ by the incumbent is $m_{2 S I}$ and equilibrium prices charged by the incumbent and new entrant are $p_{i 2 S I}$ and $p_{e 2 S I}$ respectively. Similarly, when the silently innovating incumbent fails, the equilibrium market share is $m_{2 \overline{s I}}$. The equilibrium prices upon failure to deliver are $p_{i 2 \overline{S I}}$ and $p_{e 2 \overline{S I}}$. The profit functions of the incumbent and the new entrant are similar to equations (1.2) and (1.4). However, the public signal that the entrant and consumer has regarding the success of the incumbent regarding delivery of the next technology frontier is $\psi_{s}$.

\subsection{Silent Incumbent Did Not Innovate in Stage 1}

When the silent incumbent chooses not to innovate, there is no notion of success or failure. The incumbent continues to deliver technology with capability $c$ in stage 2 albeit the incumbent still incurs a reputation cost based on the public signal $\psi_{s}$ regarding the incumbent's success. The utility of the indifferent consumer is

$$
\begin{aligned}
& U_{i 2 S}=c+\left(\alpha_{i}-t\right) m_{2 S}-p_{i 2 S} \\
& U_{e 2 S}=c+\Delta_{e}+\left(\alpha_{e}-t\right)\left(1-m_{2 S}\right)-p_{e 2 S}
\end{aligned}
$$

Firms' profits are given as

$$
\begin{aligned}
& \pi_{i 2 S}=p_{i 2 S} m_{2 S}-\psi_{S} m_{1 S} \\
& \pi_{e 2 S}=p_{e 2 S}\left(1-m_{2 S}\right)
\end{aligned}
$$

Proposition 1: The stage 2 equilibrium prices of the incumbent and the entrant firm increases in $t$ and decreases in network effect parameters $\left(\alpha_{i}, \alpha_{e}\right)$. The equilibrium prices decreases at a higher rate with respect to the network effect parameter of the competing firm.

\section{[All proofs are in the Appendix]}

Higher the transportation cost parameter $t$, higher is the disutility faced by the consumer from moving away from their ideal taste preference on the Hotelling line. Some products could be addictive and such habit forming products have high $t$. In such markets firms can charge a premium from consumers based on the strength of consumer's taste preference. The presence of network effects reduces the price that the firm can charge because the firm has to offer more competitive prices in order to balance benefits of consumers with the competing firm. This suggests that prices are more competitive for products like cellphones, gaming consoles, etc. where network effects play a role. We will revisit the impact of network effect parameters in Section 5.

\section{Stage 1 Analysis}

In stage 1 , the incumbent firm sets prices in accordance with the rational expectations of consumers and entrant based on public signal and incumbent's preannouncement strategy. However, the incumbent firm has better information about the success of innovation of the next technology frontier. Thus, while making a decision on which preannouncement and innovation strategy to engage in, it takes its private signal into consideration. We 
analyze the incumbent's preannouncement and pricing strategies in stage 1 .

\subsection{Truthful Preannouncement}

In this scenario, the utility of a consumer indifferent between the incumbent and new entrant is given as

$$
\begin{aligned}
& U_{i 1 A}=c+\left(\alpha_{i}-t\right) m_{1 A}-p_{i 1 A} \\
& +\delta\left(\psi_{A} U_{i 2 A}+\left(1-\psi_{A}\right) U_{i 2 \bar{A}}\right) \\
& U_{e 1 A}=c+\Delta_{e}+\left(\alpha_{e}-t\right)\left(1-m_{1 A}\right)-p_{e 1 A} \\
& +\delta\left(\psi_{A} U_{e 2 A}+\left(1-\psi_{A}\right) U_{e 2 \bar{A}}\right)
\end{aligned}
$$

Incumbent firm incurs development cost in stage 1 . Firm profits are given as

$$
\begin{aligned}
& \pi_{i 1 A}=p_{i 1 A} m_{1 A}-\phi \Delta_{i}^{2} \\
& +\delta\left(\psi_{A} \pi_{i 2 A}+\left(1-\psi_{A}\right) \pi_{i 2 \bar{A}}\right) \\
& \pi_{e 1 A}=p_{e 1 A}\left(1-m_{1 A}\right) \\
& +\delta\left(\psi_{A} \pi_{e 2 A}+\left(1-\psi_{A}\right) \pi_{e 2 \bar{A}}\right)
\end{aligned}
$$

In the above equations, $\delta(0<\delta<1)$ is the discount factor that consumers and firms use in order to compute the expected value from the second stage. The discount factor reflects patience level of consumers and firms for the given timing of the stages. If patience level is low, consumers and firms discount future expected value heavily and base their decision on current period utilities and profits respectively.

\subsection{Silent Innovation}

In this scenario, utility function of a consumer indifferent between the incumbent and entrant in stage 1 is similar to equation(1.7) with corresponding prices $\left(p_{i 1 S I}, p_{e 1 S I}\right)$ and public signal $\left(\psi_{s}\right)$. Further, the profit functions are similar to equation(1.8). We can compute the equilibrium prices by simultaneously solving the first order conditions of firm's profit with respect to its price. While proposition 1 extends to such prices as well, equilibrium prices upon innovation with a truthful or silent preannouncement is additionally impacted by the public signal regarding success of such an innovation effort. The equilibrium prices in stage 1 for preannouncement strategy $k \in\{A, S I\}$ are shown below.

$$
\begin{aligned}
& p_{i 1 k}=\frac{3 t-\alpha_{i}-2 \alpha_{e}-(1-\delta) \Delta_{e}+2 \delta \psi_{k}\left(1-\psi_{k}\right)}{3} \\
& p_{e 1 k}=\frac{3 t-2 \alpha_{i}-\alpha_{e}+(1-\delta) \Delta_{e}+\delta \psi_{k}\left(1-\psi_{k}\right)}{3}
\end{aligned}
$$

Proposition 2a: When the incumbent undertakes innovation in stage 1 , the equilibrium prices of both firms increase in the public signal $\psi_{k}$ if $\psi_{k}>0.5$ where $k \in\{A, S\}$ and vice versa. Further, the incumbent's price in stage 1 increases at a higher rate with $\psi_{k}$ relative to the entrant.

When the public signal is sufficiently high, incumbent can signal its commitment to innovation by charging a price that increases in the strength of the public signal. However, when the public signal is not strong enough, the incumbent can still signal its commitment to innovation by offering its product at a relatively lower price to offset expected payoff under uncertainty. This leads to some interesting dynamics for different industry scenarios. If the incumbent firm has a strong reputation for innovation (e.g., Apple) then it can charge a high price only if its announcement or silence both leads to high expectations regarding firm success. The cellphone industry has witnessed this effect with initial versions of Apple's iPhone's such as iPhone 4/4S. However, with iPhone $5 \mathrm{C}$ the expectations were very high, however the public sentiment based on Apple's silence did not serve it well [32]. This may have led to heavy discount observed with iPhone 5c post launch. Would it have been more prudent for Apple that typically believes in maintaining silence to have made a preannouncement given the low innovation levels of iPhone $5 c$ ? In the following section, we will analyze equilibrium preannouncement strategy that enables the firm to optimize its profits.

\subsection{Silent with No Innovation}

In this scenario, the incumbent firm does not undergo any cost related to innovation. The prices charged by the incumbent and entrant firms are $p_{i 1 s}$ and $p_{e 1 S}$. The utilities of indifferent user and firm profits are similar to equations (1.7) and (1.8) where the public signal is $\psi_{s}$. The equilibrium prices of firms are 


$$
\begin{aligned}
& p_{i 1 S}=\frac{3 t-\alpha_{i}-2 \alpha_{e}-\Delta_{e}+2 \delta \psi_{S}}{3} \\
& p_{e 1 S}=\frac{3 t-2 \alpha_{i}-\alpha_{e}+\Delta_{e}+\delta \psi_{S}}{3}
\end{aligned}
$$

Proposition 2b: When the incumbent does not undertake innovation in stage 1 , the equilibrium prices of both firms increase in the public signal $\psi_{s}$.

Further, the incumbent's price in stage 1 increases at a higher rate with $\psi_{s}$ relative to the entrant.

Unlike incumbent's innovation strategy, the stage 1 equilibrium prices increase in the public signal. Silence may lead to heavy speculation and generation of strong rumors though social media channels. This possibility is typically high when an incumbent of high past reputation preempts the market with 'silentware' and social media and other online channels of information dissemination lead to strong rumors. In such a scenario, an incumbent must be cautious of over enthusiasm by consumers an overtly strategic behavior by the entrant. Even if the public signal is not very strong, it helps the incumbent price its product higher as the signal strength increases. However, in the innovation strategy of the incumbent, the public signal needs to be strong enough to benefit pricing. While a preannouncement may not always be able to control the public signal, in scenarios when it can be controlled with more information via preannouncement, the incumbent benefits in doing so if its private signal is strong.

Proposition 3: When incumbent finds it profitable to undertake innovation, for a given $\sigma(>\hat{\sigma})$, there exists thresholds $\underline{\psi}_{A}, \bar{\psi}_{A}\left(\right.$ on $\left.\psi_{A}\right)$ and $\underline{\psi}_{S}, \bar{\psi}_{S}\left(\right.$ on $\left.\psi_{s}\right)$ such that the innovating incumbent chooses to

a) preannounce if $\underline{\psi}_{A}<\psi_{A}<\bar{\psi}_{A}$ and $\bar{\psi}_{S}<\psi_{S}<\underline{\psi}_{S}$.

b) remain silent if $\underline{\psi}_{S}<\psi_{S}<\bar{\psi}_{S}$ and $\bar{\psi}_{A}<\psi_{A}<\underline{\psi}_{A}$.

When the incumbent's private signal is sufficiently high, it knows that it has a high chance of success with its innovation efforts. There exists a threshold $\hat{\sigma}$ on the incumbent's private signal $\sigma$ such that the incumbent chooses to innovate if $\sigma>\hat{\sigma}$. Below this threshold, the incumbent remains silent irrespective of the public signal (refer to Figure 1 and Figure 2). This is primarily the reason why in the age of social media, silence if often interpreted as lack of innovation in industries where the technology ceiling for a product category has been reached.
A high strength of private signal does not necessarily mean that the incumbent will preannounce. Preannouncement is optimal for the firm if the public signal associated with preannouncement is moderate (refer to Figure 1a). For low and high public signals associated with preannouncement, an innovating firm should remain silent since these two regions are marked by market pessimism (low $\psi_{A}$ ) and optimism (high $\psi_{A}$ ) respectively. Committing to consumers via preannouncement leads to high ex-post cost in both scenarios. By contrast, if the public signal generated by silence leads to market pessimism (low $\psi_{s}$ ) or optimism (high $\psi_{s}$ ), firm is better off preannouncing in order to improve its ability to price in these regions of operations provided the expected public signal associated with preannouncement makes such a strategy feasible (refer to Figure 1b). The incumbent must be cautious in understanding the interplay between such public and private signals before choosing its preannouncement and innovation strategy.

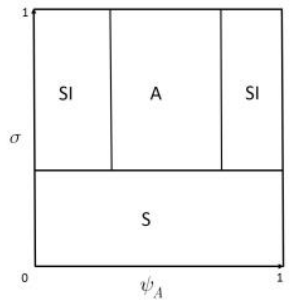

Fig. 1a.

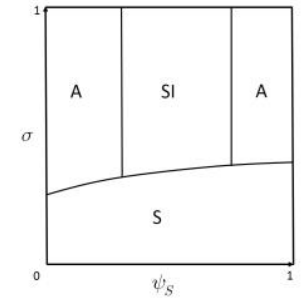

Fig. 1b.
Figure 1. Preannouncement strategies for variation in incumbent's private signal and public signal.

In Figure 2, the role of private information is illustrated in three scenarios. Figure 2a depicts the scenario when the private signal of the incumbent is low. In this case, the incumbent does not innovate if the public signal associated with silence $\left(\psi_{s}\right)$ is high irrespective of the public signal associated with announcement $\left(\psi_{A}\right)$. When $\psi_{s}$ is low, the incumbent finds it optimal to innovate while it preannounces only for moderate levels of $\psi_{A}$. Figure $2 b$, illustrates how the no innovation region (Strategy $S$ ) shrinks as the strength of private signal improves and is in the moderate range while this region vanishes when the private signal is high. Further, for a given $\psi_{A}$, the innovating firm remains silent for moderate values of 
$\psi_{s}$ and preannounces otherwise. Figure $2 \mathrm{c}$ is consistent with our understanding from Proposition 3 and Figures 1 and 2 . We use the following parameters for numerical illustrations in Figures 1, 2 and 3.

$t=2, \delta=0.5, \alpha=0.2, \delta=0.5, \Delta_{i}=2.2, \Delta_{e}=2, \phi=0.1$.

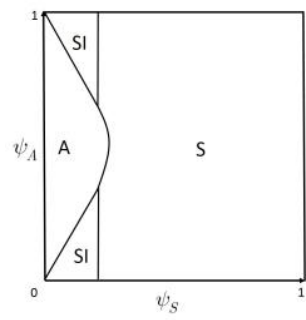

Fig. $2 \mathrm{a} \sigma=0.4$

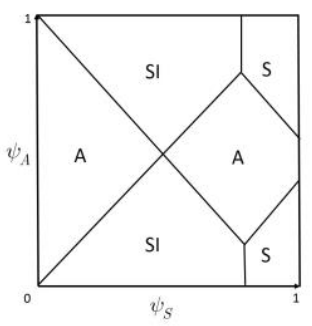

Fig. 2b. $\sigma=0.5$

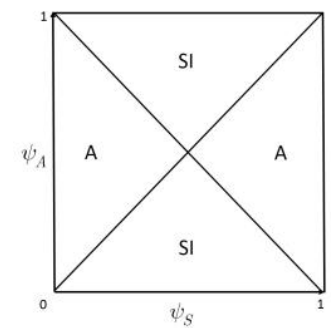

Fig. 2 c. $\sigma=0.9$

Figure 2. Preannouncement strategies for variation in public signals for different private signals.

Next we analyze the role of network effect parameter on the incumbent's preannouncement strategy.

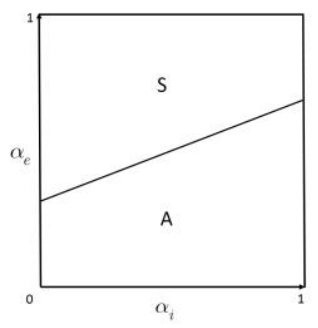

Fig. 3a.

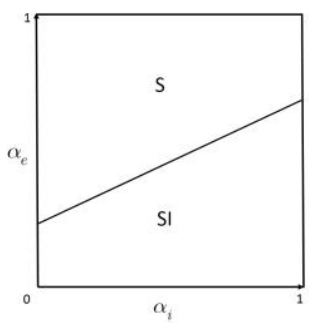

Fig. 3b.
$\psi_{A}=0.6, \psi_{s}=0.2, \sigma=0.6 . \quad \psi_{A}=0.2, \psi_{s}=0.6, \sigma=0.6$.

Figure 3. Preannouncement strategies for variation in network effect parameters.

Proposition 4: Innovation is optimal for the incumbent if the ability of the new entrant to leverage network effect is low.
In Figure 3, we use similar parameters as in Figure 2 to identify the incumbent's optimal preannouncement strategy. Competing firms may have different abilities to leverage network effects. This is captured by the network effect parameters $\alpha_{i}$ and $\alpha_{e}$. These parameters impact consumer's utility. We find that when the entrant has higher ability to leverage network effect compared to the incumbent $\left(\alpha_{e}>\alpha_{i}\right)$, there exists a preannouncement strategy where the incumbent innovates only for low values of $\alpha_{e}$. This is because high network effect parameters negatively impact firm's pricing and its ability to profit as discussed in Proposition 1.

\section{Conclusion}

In technology product networks with switching costs, incumbent networks often use preemption strategies like the preannouncement of future technologies in order to dissuade users from migrating to the new entrant with superior technology. However, not all preemption strategies succeed. While some firms are better off making committed preannouncements, others find remaining silent to be the best strategy. However, based on the several factors like firm's reputation, the saturation of technology, speculation on social media and other channels a public perception regarding the success of the incumbent is created. Managing expectations has become increasingly difficult in the presence of social media. Such media channels often generate inaccurate perceptions leading to market pessimism or optimism. The firm however has private information regarding the success of its product and must take into consideration such private signal in order to design its preannouncement strategy.

We use a stylized model to understand the impact of uncertainties in public and private signals and network effects on preannouncement strategies. We find that the incumbent follows a preannouncement strategy (truthful or silent) if the public signal associated with it is moderate. Further, network effects has a negative impact on prices and incumbent may innovate only if the entrant's relative ability to leverage network effects is low. Possible extensions of this research could analyze the impact of asymmetric evaluation of the public signal by the entrant and consumers on preannouncement strategies. In absence of empirical or theoretical work to understand preannouncement strategies under uncertainties that mark modern settings in the age of social media, the insights from this paper provide early contribution to this area of research. 


\section{References}

[1] Armstrong, M. (2006). Competition in two-sided markets. The RAND Journal of Economics, 37(3), 668-691.

[2] Bayus, Barry L.; Jain, Sanjay; Rao, Ambar G. (200102-01). "Truth or consequences: An analysis of vaporware and new product announcements". Journal of Marketing Research(American Marketing Association) 38 (1): 3-13

[3] Beggs, A.W. and Klemperer, P. "Multi-period Competition with Switching Costs." Econometrica, Vol. 60 (1992), pp. 651-666.

[4] Calantone, R.J. and Schatzel, K.E. (2000). Strategic Foretelling: Communication- based Antecedents of a Firm's Propensity to Preannounce. Journal of Marketing 64(1):17-30.

[5] Choi, Jay Pil, Eirik Gaard Kristiansen, and Jae Nahm. "VAPORWARE*."International Economic Review 51.3 (2010): 653-669.

[6] Dranove, D. and Gandal, N. (2003). The DVD-vs.DIVX Standard War: Empirical Evidence of Network Effects and Preannouncement Effects. Journal of Economics and Management Strategy. 12(3):363-386.

[7] Eliashberg, J. and Robertson, T.S. (1988). New Product Preannouncing Behavior: a Market Signaling Study. Journal of Marketing Research 25(3):282-292.

[8] Farrell, J. and Saloner, G. (1986). Installed Base and Compatibility: Innovation, Product Preannouncement, and Predation. American Economic Review 76(5):940-955.

[9] Farrell, J. "Cheap Talk, Coordination, and Entry." RAND Journal of Economics, Vol. 18 (1987), pp. 34-39.

[10] Farrell, J. and Shapiro, C. "Dynamic Competition with Switching Costs." RAND Journal of Economics, Vol. 19 (1988), pp. 123-137.

[11] Fisher, F.M., McGowan, J.J., and Greenwood, J.E. (1983). Folded, Spindled, and Mutilated: Economic Analysis and U.S. V. IBM. Cambridge: Massachusetts Institute of Technology Press.

[12] Gerlach, H.A.. "Announcement, entry, and preemption when consumers have switching costs." , RAND Journal of Economics, 2004, Vol. 35, No. 1, Spring 2004, pp. 184202.

[13] Heil, O. and Robertson, T.S. (1991). Toward a Theory of Competitive Market Signaling: a Research Agenda. Strategic Management Journal 12:403-418.

[14] Hotelling, H. (1990). Stability in competition (pp. 5063). Springer New York.

[15] Kahney, Leander (2005-01-07). "Vaporware Phantom Haunts Us All". Wired News.
[16] Katz, M.L. and Shapiro, C., 1985, "Network externalities, competition, and compatibility", The American Economic Review, Vol. 75, No. 3 (June), pp. 424-440.

[17] Kohli, C. (1999). Signaling New Product Introduction: a Framework Explaining the Timing of Preannouncement Journal of Business Research 46:45-56.

[18] Landis, R.C. and Rolfe, R.S. (1985). Market Conduct under Section 2:When Is It Anticompetitive? In: Antitrust and Regulation: Essays in Memory of John J. McGowan, ed. F.M. Fisher. Cambridge: Massachusetts Institute of Technology Press, 131-152.

[19] Lilly, B. and Walters, R. (1997). Toward a Model of New Product Preannouncement Timing. Journal of Product Innovation Management 14:4-20.

[20] Su, Meng and Rao, Vithala R., (2011), Timing decisions of new product preannouncement and launch with competition, International Journal of Production Economics, 129, issue 1, p. 51-64.

[21] Mohen, Joseph (1989-06-19). "Seeking a cure for the vaporware epidemic". Network World (IDG Network World) 6 (24): 32

[22] Messmer, Ellen (1990-10-22). "Software firms form group to raise ethics". Network World (IDG Network World) 7 (43): 9.

[23] Ofek, E., \& Turut, Ö. (2013). Vaporware, suddenware, and trueware: new product preannouncements under market uncertainty. Marketing Science,32(2), 342-355.

[24] Popma, Wybe T., Waarts, Eric and Wierenga, Berend, New Product Announcements as Market Signals. A Content Analysis in the Dram Chip Industry (July 2003 5,). ERIM Report Series Reference No. ERS-2003-025-MKT.

[25] Rao, V. R., "Methods for Handling Massive Numbers of Attributes in Conjoint Analysis" Review of Marketing Research 5 (2008): 104-129.

[26] Schatzel, K.E., Calantone, R.J., and Droge, C. (2001). Beyond the Firm's Initial Declaration: Are Preannouncement of New Product Introductions and Withdrawals Alike? Journal of Product Innovation Management 18:82-95.

[27]WebLink:http://www.pcworld.com/article/186172/ microsoft_HP_tablet.html

[28]WebLink:http://www.pocketlint.com/news/38452/appl e-ipad-vs-hp-touchpad

[29]WebLink:http://EzineArticles.com/6119151 
[30]WebLink:http://forums. webosnation.com/ archive/ index.php?t-285292.html

[31]WebLink:http://www.popherald.com/hp-touchpad-4gcheaper-than-ipad-2-counterpart-amazon-pre-order-pagereveals-9669

[32]WebLink: http://www.macworld.com/article/ 3052938 /ios/an-appointment-with-disappointment-reaction-to-theiphone-se-is-predictable.html

\section{APPENDIX: Proofs of Propositions}

Proof of Proposition 1: Equating utilities of the indifferent consumer in equation(1.1), we derive the equilibrium market share of the incumbent for strategy $A$ as follows

$$
m_{2 A}=\frac{p_{c 2 A}-p_{i 2 A}+t-\alpha_{e}+\Delta_{i}-\Delta_{e}}{2 t-\left(\alpha_{i}+\alpha_{e}\right)}
$$

Simultaneously solving the first order condition of the profit functions in equation(1.2), the equilibrium prices are

$$
\begin{gathered}
p_{i 2 A}=\frac{3 t-\alpha_{i}-2 \alpha_{e}+\Delta_{i}-\Delta_{e}}{3} \\
p_{e 2 A}=\frac{3 t-2 \alpha_{i}-\alpha_{e}-\left(\Delta_{i}-\Delta_{e}\right)}{3}
\end{gathered}
$$

Similarly, from equations (1.3) and (1.4),

$$
\begin{aligned}
& p_{i 2 \bar{A}}=\frac{3 t-\alpha_{i}-2 \alpha_{e}-\Delta_{e}}{3} \\
& p_{e 2 \bar{A}}=\frac{3 t-2 \alpha_{i}-\alpha_{e}+\Delta_{e}}{3}
\end{aligned}
$$

We can compute similar pricing for strategy $S I$.

For strategy $S$, from equations(1.5) and (1.6), we can derive the equilibrium stage 2 prices for silent strategy as follows.

$$
\begin{aligned}
& p_{i 2 S}=\frac{3 t-\alpha_{i}-2 \alpha_{e}-\Delta_{e}}{3} \\
& p_{e 2 S}=\frac{3 t-2 \alpha_{i}-\alpha_{e}+\Delta_{e}}{3}
\end{aligned}
$$

For a given strategy $k \in\{A, S I, S\}$,

$$
\frac{\partial p_{12 k}}{\partial t}=1, \frac{\partial p_{i 2 k}}{\partial \alpha_{i}}=-\frac{2}{3}, \frac{\partial p_{12 k}}{\partial \alpha}=-\frac{1}{3} .
$$

Proof of Proposition 2: From equation(1.9), $\frac{\partial p_{i 2 k}}{\partial \psi_{k}}=\frac{2 \delta}{3}\left(1-2 \psi_{k}\right) \quad, \quad \frac{\partial p_{i 2 k}}{\partial \psi_{k}}=\frac{\delta}{3}\left(1-2 \psi_{k}\right) . \quad$ Thus, when $\psi_{k} \geq 0.5, \frac{\partial p_{i 2 k}}{\partial \psi_{k}} \geq 0, \frac{\partial p_{c 2 k}}{\partial \psi_{k}} \geq 0$. Otherwise the prices decreases in the public signal. Similarly from equation(1.10), Proposition $2 \mathrm{~b}$ follows.

Proof of Proposition 3: From the profit functions of the innovation strategy and no innovation strategy, we can derive $\hat{\sigma}$ - the threshold above which innovation is optimal. When $\sigma$ is sufficiently high, in this region, we compare the profit functions of preannouncement and silent innovation to compute $\underline{\psi}_{A}, \bar{\psi}_{A}, \underline{\psi}_{S}, \bar{\psi}_{S}$. The expressions have been omitted in this version in the interest of space and are available upon request.

Proof of Proposition 4: The profit functions of the incumbent incorporates private signal for the probability of success of the innovation, and public signal by substituting prices derived in stage 1 and 2 For preannouncement strategy $k \in\{A, S I, S\}$, the incumbent's profit is given as follows.

$$
\pi_{i 1 k}=p_{i 1 k} m_{1 k}-\phi \Delta_{i}^{2}+\delta\left(\sigma \pi_{i 2 k}+(1-\sigma) \pi_{i 2 k}\right)
$$

We can derive the value of $\alpha_{e}$ that makes the incumbent indifferent between innovating and not innovating, i.e., $\pi_{i 1 \mathrm{~A}}=\pi_{i 1 \mathrm{~s}}$. Let us call this threshold $\alpha_{e A}$. Similarly, $\alpha_{e s l}$ is the value of $\alpha_{e}$ that makes the incumbent indifferent between silent innovation and no innovation. Above this threshold, Silence is the dominant strategy and below this threshold the incumbent's optimal strategy is to innovate (silently or with preannouncement). 